\title{
Declaração Universal dos Direitos Humanos: autoridade, significado e natureza jurídica ${ }^{1}$
}

\section{The Universal Declaration of Human Rights: Authority, Meaning and Legal Nature}

\author{
Fredys Orlando Sorto ${ }^{2}$ \\ Universidade Federal da Paraíba (Brasil)
}

Recibido: 27-07-18

Aprobado: 24-08-18

\section{Resumo}

Por muitos anos vigeu a idéia de que somente os Estados são sujeitos de Direito internacional. Atualmente é inegável a existência de outros sujeitos, dentre os quais a pessoa humana. Este artigo trata do movimento que consagra o ser humano como sujeito de direitos e analisa o principal instrumento declarativo desses direitos da sociedade internacional: a Declaração Universal dos Direitos Humanos (1948). Trata-se de documento incomparável na História da Humanidade, porque é um documento revolucionário que provoca mudanças profundas de mentalidade e de atitude no mundo.

Palavras-chave: Declaração de Direitos. Declaração Universal dos Direitos Humanos.

\footnotetext{
${ }^{1}$ A versão original do presente texto foi publicada na Revista: Verba Juris: Anuário da PósGraduação em Direito, João Pessoa, ano 7, n. 7, p. 9-34, jan./dez. 2008. A versão atual está aumentada e corrigida. Confesso, caro leitor, que mudei de posição em relação a vários pontos do texto original. Assim, por exemplo, não me parece mais que a Declaração seja realmente "universal" nem que haja direitos inatos (são todos históricos). Leituras posteriores contribuíram para tal mudança (destaco, dentre outros, apenas dois autores: Ernst Bloch, com respeito aos direitos inatos; François Jullien, no que se refere à universalidade).

2 (sortofredys@hotmail.com). Mestre em Direito Internacional e Doutor em Ciência Política pela Universidade de São Paulo. Atual Diretor do Centro de Ciências Jurídicas da Universidade Federal da Paraíba. Professor Titular da UFPB (Departamento de Direito Público). Obras destacadas: Sorto, Fredys Orlando (Org.). O pensamento jurídico entre Europa e América: estudos em homenagem ao Professor Mario G. Losano. Porto Alegre: Sergio Antonio Fabris, 2018. Guerra civil contemporânea: a ONU e o caso salvadorenho. Porto Alegre, 2001; "La compleja noción de solidaridad como valor y como derecho. La conducta de Brasil en relación a ciertos Estados menos favorecidos". In: Solidaridad y derechos humanos en tiempos de crisis. Madrid: Dykinson, 2011. pp. 97-124; "The Freedom of the Seas" ("Mare Liberum" by Hugo Grotius): "Importance and topicality". In: América Latina y el derecho del mar. Valencia: Tirant lo Blanch, 2018. pp. 35-50.
} 


\begin{abstract}
The idea that only the State is subject to International Law lingered for many years. At present it is undeniable the existence of other subjects, among which, the human being. This article deals with the movement which acclaims the human being as subject to rights and analyses the main declarative instrument of these rights in the international society: The Universal Declaration of Human Rights (1948). It is an incomparable document in the History of Mankind, for it is a revolutionary document that causes profound changes of mentality and attitude in the world.
\end{abstract}

Key-words: Declaration of Rights. Universal Declaration of Human Rights.

Termos do Problema: Qual a natureza jurídica, o valor ético e o efetivo alcance protetor em matéria de Direitos Humanos desse instrumento internacional tão invocado, citado e reverenciado que atende pela denominação de Declaração Universal dos Direitos Humanos?

\title{
Introdução
}

Kwame Appiah inicia o seu livro Cosmopolitismo: a ética em um mundo de estranhos asseverando que "Faz muito tempo que nossos antepassados são seres humanos". Realmente, faz milênios. Contudo, o fato de as pessoas terem esses caracteres herdados de há muito não é suficiente de per se para torná-las portadoras de direitos em todos os lugares e tempos. A maioria das pessoas seguramente passou pela vida sem gozar essa humanidade; outros viveram e lutaram com dignidade, trata-se dos visionários da liberdade e dos destemidos, que desafiaram a escravidão, dos que entregaram as suas vidas em benefício da causa de tornar a pessoa humana titular de direitos, primeiro dentro da comunidade política particular, depois no mundo. Embora a declaração seja intitulada de "universal". Mas essa universalização de direitos, que não é aceita por todos, é fato bastante recente.

Reputo lícito, desde logo, esclarecer a questão do âmbito espacial de aplicação da Declaração Universal dos Direitos Humanos. Poder-se-ia dizer, com propriedade, que a Declaração se aplica realmente em todo o universo? Claro está que no passado o geocentrismo era incontestável. Quem ousaria na Antiguidade se opor, por exemplo, à autoridade de Aristóteles ou ao "Almagesto" de Ptolemeu? O fato é que a teoria do universo geocêntrico perpassa a Idade Média praticamente incólume. Somente na Modernidade essa falsa teoria, tão conveniente à Igreja Católica e a muitos governantes, é submetida a prova, 
restando demonstrada enfim a sua falsidade científica. Considere-se ainda o seguinte: supondo que realmente haja seres humanos fora da Terra, como legislar em seu nome sem que eles tenham delegado poderes específicos para representá-los? Vista assim a questão, o universalismo não faz sentido. Tratase de erro notável tomar a Terra pelo Universo, ressalvadas, naturalmente, certas licenças poéticas. Se a Declaração não se aplica no Universo inteiro então, obviamente, não é universal. Trata-se, na verdade, de documento imprescindível de Direito internacional dos Direitos Humanos aplicável tão somente aos habitantes do planeta Terra.

Retornando à asserção de Appiah, poder-se-ia ir mais longe e afirmar que embora os seres humanos sejam dotados de natureza humana há bastante tempo, eles estão realmente juntos há cerca de pouco mais de quinhentos anos, desde o descobrimento do Novo Mundo. É nesse breve espaço temporal que se dão os grandes fatos que negam e afirmam simultaneamente direitos. Negam-se quando se constróem sistemas socioeconômicos baseados na escravização de pessoas, quando se tortura em nome da fé e por quaisquer outros motivos cruéis, quando se pune sem observar o devido processo legal; negam-se, especialmente, quando não se respeita a vida, quando o ser humano pode ser descartado, como nos eventos históricos marcados pelos totalitarismos (nazismo e stalinismo). Por outro lado, afirmam-se os direitos humanos quando eles são positivados em instrumentos aceitos juridicamente como vinculantes pelos Estados, quando essa codificação é acompanhada dos devidos mecanismos de conscientização, fiscalização e garantia; quando se estabelecem políticas preventivas visando à remoção das causas que motivam violações.

Noutro trecho da referida obra, $\mathrm{Appiah}^{3}$ diz que "O desafio é, então, pegar a mente e o coração formados ao longo dos milênios em que convivemos em pequenas comunidades, e equipá-los com ideias e instituições que nos permitam viver juntos como na tribo global na qual nos tornamos". Com efeito, a vida humana em comum é realmente incontornável. Mas é preciso lembrar que, mesmo considerando essa inevitabilidade da convivência, não faz tanto tempo assim que os seres humanos estão juntos nesse espaço global. Efetivamente, cinco séculos atrás havia muito menos pessoas, a sociedade de então era menos complexa. O Novo Mundo recém-descoberto tinha seres cuja alma, direitos de propriedade, e condição humana eram ainda discutíveis para alguns. Mas é o descobrimento do outro, do diferente, que alarga e generaliza a ideia de mundo e de indispensabilidade da convivência. Claro está que para chegar a isso se passou pelo genocídio de milhões de pessoas quer no Novo Mundo, mediante o aniquilamento de civilizações, quer na "Europa civilizada", promotora de duas guerras mundiais atrozes no século passado. Não bastasse isso, a história da construção dos direitos humanos da sociedade política internacional passou, e

\footnotetext{
${ }_{3}$ Appiah, Kwame Anthony: Cosmopolitismo: la ética en un mundo de extraños. 2007. p. 15. 
ainda passa, pela intolerância religiosa, econômica e cultural. É difícil pensar no sucesso da vida em comum quando se valoriza o que é diferente e se esquece o que é comum, quando não se considera o que é essencial e se enfatiza o que é particular. De fato, o que importa é, realmente, o que é comum e essencial aos seres humanos.

O reconhecimento dessa natureza humana dotada de direitos não tem sido fácil. $\mathrm{O}$ esforço pela legitimação de direitos percorre a história das ideias e dos fatos, das afirmações e das negações. Passa-se primeiro pelo reconhecimento de que certos direitos são inerentes à pessoa humana, principalmente o da vida e o da liberdade. Trata-se de prerrogativas que já nascem com a pessoa, conforme certas correntes jusnaturalistas, cujas elaborações teóricas vão desde a versão estoica à iluminista, esta nitidamente revolucionária e afirmadora de direitos "cosmopolitas" no plano interno. A par dessa afirmação de princípios racionais (cujo inatismo Ernst Bloch demonstra ser falso), acham-se os direitos decorrentes de conquistas históricas. Estes se dão no Estado moderno, especialmente, com as revoluções liberais francesa e estadunidense, que promovem os direitos individuais (civis e políticos). Ademais da revolução industrial, que ajuda a estabelecer em grande medida os direitos sociais.

O Estado que emerge na modernidade é fulminado por essas ondas revolucionárias, que pouco a pouco formam os catálogos de direitos que aparecem em todas as Constituições contemporâneas. Se de um lado esse espaço estatal abre a possibilidade do diálogo permanente entre os pares da comunidade política; de outro, nega-se a muitos a fruição de direitos essenciais como a liberdade e a igualdade. Deste lado estão negros escravizados, pobres excluídos da política e da vida digna, mulheres privadas de todos os direitos.

Não se pode dizer, por conseguinte, que a sociedade internacional sempre reconhecera o ser humano como detentor de direitos e obrigações. Reconhece-o como tal somente depois das tragédias bélicas do século XX. Aparece desta sorte a primeira declaração de Direitos da Humanidade, que é a Declaração Universal dos Direitos Humanos, e só depois da II Guerra Mundial. Assim, a assertiva de que o 'homem' tem direitos é mesmo anterior à formação da sociedade estatal. Mas, a asserção de que a pessoa humana tem certos direitos e obrigações, com reconhecimento internacional, é bem posterior.

A recognição das referidas prerrogativas assegura no papel a condição de sujeito de direito da pessoa humana no marco internacional. Contudo, mesmo com a codificação de muitos direitos, outros, porém, ainda continuam negados na prática. Não é preciso ir longe para verificar isso, basta lembrar os problemas decorrentes da pobreza extrema na África e na América Latina, da intensa imigração de pobres para os países ricos, do subdesenvolvimento, dos deslocamentos forçados, da intolerância racial e religiosa. Além do mais, há problemas culturais presentes que decorrem da visão de mundo de determinadas 
sociedades, que enfatizam o relativo em detrimento do que é comum. De fato, aprofundou-se o relativismo cultural, que é a especificidade, em prejuízo do que é geral.

Não se deve subestimar o tema do multiculturalismo, porque ele mantém intensa vinculação com a problemática acima enunciada. No caso da DUDH alega-se que ela também padece do mal do relativismo, pois é fruto das tradições culturais ocidentais que não correspondem às de outros povos, notadamente os que violam de modo contumaz os direitos humanos. O ponto é que há valores que de fato são particulares, razão pela qual devem ser respeitados, desde que eles, naturalmente, não conflitem com os valores que são "universais", isto é, os que constituem o núcleo duro dos direitos humanos. Volta-se, assim, à tese da necessidade de afirmar o que é comum em benefício da humanidade, em vez de sancionar o que é particular, relativo e temporário, ou antes, o que interessa a alguns por diversas motivações, dentre as quais as que tratam da manutenção do poder em Estados governados por regimes políticos autoritários. É óbvio que não se devem tolerar violações de direitos já consagrados como normas de ius cogens (imperativas) na sociedade internacional ${ }^{4}$, dado que os direitos com dignidade maior devem prevalecer sobre os de menor valor. Assim, por exemplo, dentre outros, o de liberdade deve ter primazia em relação ao de propriedade (vedando a escravidão). Na superação dessa problemática certamente a Educação e o desenvolvimento têm papéis de grande importância. A referência não é a qualquer tipo de educação, mas à Educação que forma cidadãos comprometidos com a comunidade política à qual pertencem e igualmente comprometidos com os valores comuns da Humanidade.

É indiscutível que a cada dia a sociedade internacional parece menor, o mundo torna-se mais homogêneo e próximo em hábitos e em valores. Não parece por consequência impossível a adoção de determinada ética internacional, ou "cosmopolita", com o que há de comum entre os povos, com o que há de valioso e geral na espécie humana. Nesse sentido a Declaração Universal dos Direitos Humanos representa, apesar das críticas, o passo mais avançado no caminho da compreensão do que é convergente. A Declaração significa um gigantesco passo adiante, deixando para trás as estupidezes que enlutaram gerações de seres humanos. A verdade é que a pessoa humana não tem outra saída a não ser procurar formas inteligentes e éticas de bem viver em comum.

\footnotetext{
4 A Convenção de Viena sobre Direito dos Tratados (1969) estabelece (Art. 53) a nulidade do tratado que violar norma imperativa de direito internacional. [Art. 53. Tratado em conflito com uma norma imperativa de direito internacional geral (ius cogens): "É nulo o tratado que, no momento de sua conclusão, conflita com uma norma imperativa de direito internacional geral. Para os fins da presente Convenção, uma norma imperativa de direito internacional geral é uma norma aceita e reconhecida pela comunidade internacional dos Estados no seu conjunto, como norma da qual nenhuma derrogação é permitida e que só pode ser modificada por nova norma de direito internacional geral da mesma natureza"].
}

Araucaria. Revista Iberoamericana de Filosofia, Política, Humanidades y Relaciones Internacionales, año 20, $\mathrm{n}^{\circ} 40$. Segundo semestre de 2018. Pp. 209-232. ISSN 1575-6823 e-ISSN 2340-2199 doi: 10.12795/araucaria.2018.i40.09 


\section{Processo de construção e desconstrução dos direitos humanos}

A construção afirma-se pelo reconhecimento da personalidade jurídica do ser humano, pela limitação do papel do Estado nesta matéria. Dáse a desconstrução pela negação do ser humano como sujeito, pela sua descartabilidade como a ocorrida nos regimes totalitários e ditatoriais.

O reconhecimento da personalidade internacional do ser humano pelo Direito das Gentes constituiu realmente grande progresso na sociedade internacional, porque de súdito (do Estado, do qual recebe proteção diplomática) ele se transforma em sujeito de direitos (cidadão do mundo, protegido pelo Direito internacional). Por consequência, a pessoa humana passa a contar com sistema subsidiário de proteção situado além das fronteiras estatais. Esse longo processo de desenvolvimento da personalidade e da dignidade humana dá-se pela articulação de ações afirmativas de recognição internas e internacionais.

Nesse percurso, certificador de direitos, importa lembrar que a DUDH teve precedentes históricos significativos no Direito interno. De fato, no século XVIII surgem as primeiras declarações de direitos humanos. Em 1776, a Declaração de Virgínia (claramente iluminista) ${ }^{5}$ e principalmente a Declaração de Independência dos Estados Unidos (1776) ${ }^{6}$. Esta afirma como verdades evidentes por si mesmas "[...] que todos os homens são criados iguais, dotados pelo Criador de certos direitos inalienáveis, que entre estes estão a vida, a liberdade e a procura da felicidade". O documento revela pontos expressivos, tais como o da essencialidade intemporal do direito à vida e à liberdade, o da "universalidade" dos direitos humanos, a progênie jusnaturalista de direitos inatos e inalienáveis, o da limitação dos poderes do Estado, o direito de resistência ${ }^{7}$. Trata-se, como se vê, de ponto de partida na construção dos direitos

${ }^{5}$ A Declaração de Direitos da Virgínia data de 12 de Junho de 1776. Note-se o teor do artigo primeiro dessa Declaração em relação ao jusnaturalismo e à autoridade que exerce na Declaração de Independência: "Artigo $1^{\circ}$ - Todos os homens nascem igualmente livres e independentes, têm direitos certos, essenciais e naturais dos quais não podem, por nenhum contrato, privar nem despojar sua posteridade: tais são o direito de gozar a vida e a liberdade com os meios de adquirir e possuir propriedades, de procurar obter a felicidade e a segurança". ["Article 1 . That all men are by nature equally free and independent, and have certain inherent rights, of which, when they enter into a state of society, they cannot, by any compact, deprive or divest their posterity; namely, the enjoyment of life and liberty, with the means of acquiring and possessing property, and pursuing and obtaining happiness and safety"].

${ }^{6} \mathrm{O} 2 .{ }^{\circ}$ Congresso Continental aprovou, em 4 de julho de 1776, a Declaração de Independência dos Estados Unidos da América, que foi redigida na sua maior parte por Thomas Jefferson. Desde 1781 Os Artigos da Confederação serviram de instrumento jurídico no governo das 13 Colônias independentes. A Constituição foi elaborada somente em 1787, sem a participação de Rhode Island, entrando em vigor no ano seguinte em substituição aos Artigos da Confederação.

${ }^{7} \mathrm{O}$ trecho completo da declaração em que se afirma o poder do povo para restringir os poderes estatais é este: "We hold these Truths to be self-evident, that all Men are created equal, that they are endowed by their Creator with certain unalienable Rights, that among these are Life, Liberty, and the pursuit of Happiness - That to secure these Rights, Governments are instituted among Men, deriving their just Powers from the Consent of the Governed, that whenever any Form of Government becomes 
humanos atuais. Por isso, o instituto da igualdade, que é o mais frágil nessa relação, será "aperfeiçoado" gradualmente. Atos posteriores, notadamente as emendas à Constituição dos Estados Unidos, comprovam essa construção por graus $^{8}$ de "igualdade".

O segundo documento iluminista afirmativo dos direitos humanos individuais e coletivos é a Declaração dos Direitos do Homem e do Cidadão (Déclaration des droits de l'homme et du citoyen, 1789). Trata-se de prestigioso instrumento interno, de categórica repercussão mundial. Ele se inspira claramente na Declaração de Independência dos Estados Unidos, aquela, como se sabe, exerceu grande autoridade na posterior Declaração Universal das Nações Unidas de 1948. No preâmbulo da Declaração francesa, a Assembleia Nacional considera que "[...] a ignorância, a negligência ou o desprezo dos direitos humanos são as únicas causas das calamidades públicas e da corrupção dos governos", razão por que "[...] resolveram expor numa declaração solene os direitos naturais, inalienáveis e sagrados do homem [sic]". Pode-se dizer que os três primeiros dispositivos da Declaração em pauta constituem o seu núcleo doutrinário. No primeiro artigo, afirma-se que "Os homens nascem e são livres e iguais em direitos"; em seguida, diz-se que a finalidade de toda a organização política "[...] é a conservação dos direitos naturais e imprescritíveis do homem. Esses direitos são a liberdade, a propriedade, a segurança e a resistência à opressão". O terceiro dispositivo assegura que o princípio de toda a soberania reside no povo, princípio claramente sancionado pelo Estado democrático de direito. Se bem não mencionado nessa relação essencial, o direito à vida deduzse que esteja implícito; já o direito à propriedade, embora explícito, carece de essencialidade, sobejando ${ }^{9}$, portanto. Dado que se pode, perfeitamente, viver sem propriedade, mas não se pode viver dignamente sem liberdade.

A proteção efetiva dos direitos humanos, é interessante notar, desenvolvese de modo simultâneo com o processo de criação das organizações internacionais do século XX. A Sociedade das Nações (1919-1939), antecessora das Nações Unidas, foi a primeira organização internacional, acontecimento que representou grande avanço no campo dos direitos humanos. Mas, a bem da verdade, diga-se que a Liga das Nações não resolveu os graves problemas

destructive of these Ends, it is the Right of the People to alter or abolish it, and to institute a new Government, laying its Foundation on such Principles, and organizing its Powers in such Form, as to them shall seem most likely to effect their Safety and Happiness".

${ }^{8}$ Devem-se lembrar nessa direção: a) as dez primeiras Emendas à Constituição (1791), b) a 13 . $^{\text {a }}$ Emenda que aboliu a escravidão $(1865)$, c) a 15 . $^{\mathrm{a}}$ Emenda que permite o voto das pessoas negras (1870), d) a 19. ${ }^{\text {a }}$ Emenda que instituiu o voto feminino (1920).

${ }^{9}$ Os três artigos mencionados são estes: “1). Les hommes naissent et demeurent libres et égaux en droits. Les distinctions sociales ne peuvent être fondées que sur l'utilité commune. 2) Le but de toute association politique est la conservation des droits naturels et imprescriptibles de l'Homme. Ces droits sont la liberté, la propriété, la sûreté et la résistance à l'oppression. 3) Le principe de toute Souveraineté réside essentiellement dans la Nation. Nul corps, nul individu ne peut exercer d'autorité qui n'en émane expressément".

Araucaria. Revista Iberoamericana de Filosofia, Política, Humanidades y Relaciones Internacionales, año 20, $\mathrm{n}^{\circ} 40$. Segundo semestre de 2018. Pp. 209-232. ISSN 1575-6823 e-ISSN 2340-2199 doi: 10.12795/araucaria.2018.i40.09 
da manutenção da paz e da segurança internacionais, nem por consequência o do respeito à pessoa humana. Por isso sucumbiu, em 1939, vítima também da própria guerra, cuja missão era evitar. Claro que não foi apenas a guerra que a aniquilou. Pesa no seu declínio, do mesmo modo, o fato de ela não ser propriamente mundial, visto que os Estados Unidos não figuravam na realidade como membros. Ainda que o Presidente Woodrow Wilson (1913-1921) dos Estados Unidos tenha incentivado a criação da Liga das Nações, a qual foi inspirada em grande medida nos chamados "Quatorze pontos" do Presidente Wilson, esse Estado não ratificou a convenção porque o Congresso não aprovou a convenção.

Pouco tempo depois, ainda em plena Segunda Guerra Mundial, os Estados Unidos e o Reino Unido tornam pública a precursora Declaração de Princípios conhecida como Carta do Atlântico ${ }^{10}$. Na mesma linha de instrumentos precursores acha-se a Declaração das "Nações Unidas" de 1942, que reafirma no Preâmbulo os princípios da Carta do Atlântico, além de usar pela primeira vez a autodenominação Nações Unidas, por sugestão do Presidente dos Estados Unidos. Este documento é, na verdade, o ponto de partida para a criação das Nações Unidas ${ }^{11}$. De fato, na Conferência de Dumbarton Oaks (Washington, D. C.), em 7 de outubro de 1944, propõe-se a criação de uma organização internacional, que se denominaria Nações Unidas.

Com efeito, a Carta das Nações Unidas é sem dúvida o grande documento de defesa da paz e dos direitos humanos ${ }^{12}$, cuja declaração de direitos é materializada mais tarde com a aprovação da Declaração Universal dos Direitos Humanos, como se verá a seguir.

\footnotetext{
${ }^{10}$ A Carta do Atlântico, Declaração de Princípios feita pelo Presidente dos Estados Unidos, Franklin Roosevelt, e pelo Primeiro Ministro britânico, Winston Churchill, em 14 de Agosto de 1941, é o primeiro documento internacional, de peso, anterior à instituição das Nações Unidas. O art. 6 da Declaração reza que "Depois da destruição completa da tirania nazista, esperam que se estabeleça a paz que proporcione a todos os Estados os meios de viver em segurança dentro de suas próprias fronteiras, e aos homens em todas as terras a garantia de existências livres de temor e de privações". Ferreira de Mello diz que o principal objetivo de Churchill nesse encontro era o de convencer os Estados Unidos a declarar guerra à Alemanha. O Brasil aderiu aos seus princípios em 1943. Por sinal, o documento não foi assinado, mas enviado via telégrafo para aprovação dos respectivos governos. Cf. Mello, Rubens Ferreira de. Textos de direito internacional e de história diplomática de 1815 a 1949. 1950. p. 592.

11 No Preâmbulo da Declaração os signatários afirmam “[...] defender a vida, a liberdade, a independência e a liberdade de culto, assim como para preservar a justiça e os direitos humanos nos seus respectivos países e em outros". Abranches diz que "Pela primeira vez, uma declaração internacional consagrou o princípio de que os Estados devem preservar os direitos humanos, não só nos respectivos territórios, como nos dos outros". Abranches, C. A. Dunshee de. Proteção internacional dos direitos humanos. 1964. p. 49.
}

A Declaração foi assinada inicialmente por 26 países. Em 1945 contava com mais 19 "adesões", dentre elas, a do Brasil, feita em 8 de fevereiro de 1943.

12 A Carta das Nações Unidas foi elaborada durante a Conferência de São Francisco, fato ocorrido entre 25 de abril e 26 de junho de 1945. Foi assinada em 26 de junho de 1945, entrando em vigor em 24 de outubro do mesmo ano. A Carta, como se sabe, criou a Organização das Nações Unidas, cuja função principal é a manutenção da paz, da segurança internacionais e o respeito aos direitos humanos. 
De acordo com Abranches, a Carta da ONU nasce impregnada da "[...] mística do respeito aos direitos humanos por todos os Estados, como eixo das relações internacionais no mundo do após-guerra"13. A Carta não deixa dúvidas quanto à preocupação com o respeito aos direitos humanos, visto que o assunto está presente ao longo do texto do referido acordo internacional. Ela evidencia, desde o preâmbulo, qual é a posição que o ser humano passa a ter a partir da sua instituição. As palavras preambulares da Carta são concludentes:

Nós, os povos das Nações Unidas, resolvidos a preservar as gerações vindouras do flagelo da guerra, que por duas vezes, no espaço da nossa vida, trouxe sofrimentos indizíveis à humanidade, e a reafirmar a fé nos direitos fundamentais do homem, na dignidade e no valor do ser humano, na igualdade de direito dos homens e das mulheres.

A Carta estabelece na parte dispositiva (art. 2, § 3) que é propósito da Organização conseguir, mediante a cooperação internacional, "[...] promover e estimular o respeito aos direitos humanos e às liberdades fundamentais para todos, sem distinção de raça, sexo, língua ou religião". Essa referência eleva os Direitos humanos do plano doméstico ao internacional, negando ao Estado a partir de então o espaço de reserva nesta matéria, que é de interesse e competência da sociedade internacional e do seu direito ${ }^{14}$. Naturalmente, o trato do assunto Direitos humanos na Carta recebeu críticas, as quais são resumidas em três por Abranches $^{15}$ : a) indefinição dos direitos e das liberdades, b) "[...] falta de normas reguladoras das medidas de execução", c) a falta de um tribunal internacional para processar as violações dos Direitos humanos ${ }^{16}$. Contudo, não resta dúvida

\footnotetext{
13 Abranches, C. A. Dunshee de. Op. Cit. p. 57.

14 A Carta cuida dos Direitos Humanos também no art. 13 “1. A Assembléia Geral iniciará estudos e fará recomendações, destinados a: b) [...] favorecer o pleno gozo dos direitos humanos e das liberdades fundamentais, por parte de todos os povos, sem distinção de raça, sexo, língua ou religião". No art. 55 reafirma o direito de autodeterminação dos povos: "Com o fim de criar condições de estabilidade e bem-estar, necessárias às relações pacíficas e amistosas entre as Nações, baseadas no respeito ao princípio da igualdade de direitos e da autodeterminação dos povos, as Nações Unidas favorecerão: [...] c) o respeito universal e efetivo dos direitos humanos e das liberdades fundamentais para todos sem distinção de raça, sexo, língua ou religião". O parágrafo segundo do art. 62 estabelece que o Conselho Econômico e Social "Poderá, igualmente, fazer recomendações destinadas a promover o respeito e a observância dos direitos humanos e das liberdades fundamentais para todos". Ainda em referência ao Conselho Econômico e Social, diz o art. 68 que esse órgão "Criará comissões para os assuntos econômicos e sociais e a proteção dos direitos humanos". Na parte referente ao sistema internacional de tutela, o art. 76 preceitua que são objetivos básicos do sistema de tutela “c) Estimular o respeito aos direitos humanos e às liberdades fundamentais para todos, sem distinção de raça, sexo língua ou religião e favorecer o reconhecimento da interdependência de todos os povos".

15 Abranches, C. A. Dunshee de. Proteção internacional dos direitos humanos. Op. cit., p. 68.

16 Deve-se recordar que a Austrália propôs na Comissão do Conselho Econômico e Social, que discutiu o Projeto da Declaração Universal dos Direitos Humanos, a criação de um tribunal internacional com jurisdição universal (que ainda falta), com vistas à aplicação de sanções nos casos de violação dos Direitos humanos.
} 
de que a partir da instituição da Carta das Nações Unidas os Direitos humanos passam a gozar de novo status no mundo, passando desde então a ter dignidade sem precedentes na sociedade internacional. Por essa via, a Declaração se transformou, a despeito das críticas, em Declaração de Direitos da Humanidade.

Convém, antes de ingressar propriamente no exame da DUDH, versar sobre outro documento de notável importância, e anterior à DUDH, a saber, a Declaração Americana de Direitos Humanos. Esse documento foi oficialmente aprovado, em 2 de maio de 1948, como Declaração Americana dos Direitos e Deveres do Homem pela Resolução XXX, na IX Conferência Internacional Americana, em Bogotá (Colômbia), precedendo, portanto, a Declaração Universal em pouco mais de sete meses.

O documento americano registra, de modo lapidar, as contribuições iluministas marcadas nos mencionados instrumentos liberais. Afirma-se quanto à liberdade e à igualdade a "universalidade" dos direitos humanos, bem como a reciprocidade entre direitos e deveres no exercício da cidadania.

Todos os homens nascem livres e iguais em dignidade e direitos e, como são dotados pela natureza de razão e consciência, devem proceder fraternalmente uns para com os outros. O cumprimento do dever de cada um é exigência do direito de todos. Direitos e deveres integram-se correlativamente em toda a atividade social e política do homem. Se os direitos exaltam a liberdade individual, os deveres exprimem a dignidade dessa liberdade.

De fato, quanto à estrutura, a pioneira Declaração Americana dos direitos humanos divide-se em dois capítulos que tratam respectivamente dos Direitos (arts. 1 a 27) e dos Deveres (arts. 29 a 38) da pessoa humana. A Declaração estabelece que todo ser humano tem direito, dentre outros, à vida, à liberdade (religiosa, de expressão etc.,) à segurança e integridade da pessoa, à igualdade perante a lei, ao sufrágio e à participação no governo, à educação, à saúde, ao trabalho, à justiça, à propriedade, à nacionalidade.

A parte relativa aos deveres da Declaração Americana é de considerável importância no campo dos Direitos humanos, especialmente no que concerne aos direitos de cidadania, porquanto às vezes as afirmações contundentes de direitos conduzem ao despropósito de esquecer as obrigações, com nefandas consequências para a comunidade. A simples afirmação de direitos, sem os devidos deveres, mostra apenas um lado dos direitos de cidadania, os quais estão no coração dos direitos humanos. Sem o conteúdo da cidadania, os direitos humanos perdem a sua essência, porque não há comunidade política sem os direitos de cidadania. Neste particular, a Declaração Americana é irretocável. Porque traz não apenas o enunciado de direitos, mas também a completude da cidadania ao tratar dos seus dois elementos essenciais. Por isso e por outros méritos, ela é, com toda a justiça, o mais insigne precedente da Declaração Universal dos Direitos Humanos de 1948. 
Tanto assim que a Declaração registra, logo depois dos direitos, os principais deveres, dentre os quais estão o de convivência social de toda a pessoa em relação às outras; o dever dos pais de auxiliar, de alimentar e de educar os filhos menores, bem como os deveres destes em relação aos genitores (honrar, sempre; auxiliar, alimentar, amparar, quando necessário). É importante assinalar que certos deveres individuais estão intimamente relacionados aos direitos sociais. Assim, ao direito ao trabalho corresponde o dever de trabalhar para a obtenção dos meios necessários à subsistência; do mesmo modo, ao direito à educação corresponde o dever de educar-se, isto é, de a pessoa adquirir pelo menos a instrução primária. Poder-se-ia dizer então que o analfabetismo é fruto da carência do direito à educação e/ou do incumprimento do dever cidadão de instruir-se? Trata-se, como sabido, de direito/dever de notável significado na hora do exercício dos direitos políticos, sendo que este é também outro dever, visto que toda a pessoa tem de votar nas eleições populares, mas somente a educação proporciona o discernimento adequado na hora das decisões políticas. Além desses deveres, a Declaração Americana menciona os seguintes: o de obediência à lei, o de prestar os serviços civis e militares necessários à defesa e à conservação do Estado, o de cooperar com a assistência e previdência sociais, o de pagar impostos destinados à manutenção dos serviços públicos.

\section{Declaração Universal de Direitos Humanos (1948)}

A efetiva internacionalização da proteção dos Direitos humanos só é factível a partir da Carta das Nações Unidas, de 1945, cujo ápice modelar é a Declaração de 1948. Esse documento é, por várias razões, um marco fundamental na história dos direitos humanos. Acima de tudo porque tem o condão de devolver o ser humano ao seu devido lugar, isto é, ao centro do processo normativo e protetor, dando-lhe a titularidade e a subjetividade no plano internacional.

A Declaração Universal dos Direitos Humanos foi aprovada pela Resolução 217-A, na 3. ${ }^{a}$ Sessão Ordinária da Assembléia Geral das Nações Unidas, em Paris, em 10 de dezembro de $1948^{17}$. Logo, se não é tratado, é supérfluo dizer que ela carece de índole convencional, razão por que não vincula juridicamente os signatários.

${ }_{17}$ A Organização das Nações Unidas tinha, em 1948, apenas 58 membros. Destes, 48 votaram a favor da Resolução 217-A (Afeganistão, Argentina, Austrália, Bélgica, Birmânia, Bolívia, Brasil, Canadá, Chile, China (Taiwan), Colômbia, Costa Rica, Cuba, Dinamarca, República Dominicana, Equador, Egito, El Salvador, Estados Unidos, Etiópia, Filipinas, França, Grécia, Guatemala, Haiti, Holanda, Índia, Iraque, Irã, Islândia, Líbano, Libéria, Luxemburgo, México, Nova Zelândia, Nicarágua, Noruega, Paquistão, Panamá, Paraguai, Peru, Reino Unido, Síria, Suécia, Tailândia, Turquia, Uruguai e Venezuela.), 8 se abstiveram (Arábia Saudita, Bielorússia, Iugoslávia, Polônia, Tchecoslováquia, Ucrânia, União Soviética, União Sul-Africana). Houve 2 ausências (Honduras e Iêmen). Nenhum voto contra.

Araucaria. Revista Iberoamericana de Filosofia, Politica, Humanidades y Relaciones Internacionales, año 20, $\mathrm{n}^{\circ} 40$ Segundo semestre de 2018. Pp. 209-232. ISSN 1575-6823 e-ISSN 2340-2199 doi: 10.12795/araucaria.2018.i40.09 
Não há como nominar o autor da $\mathrm{DUDH}^{18}$. Por certo é obra coletiva que recolhe as idéias dominantes e as tradições ocidentais. Contudo, é preciso registrar que determinadas personagens tiveram participação decisiva, dentre elas, John Humphrey (Canadá) Diretor da Divisão de Direitos Humanos, responsável pela redação do primeiro rascunho da Declaração; René Cassin (França) sob cuja responsabilidade ficou a versão final do texto aprovado; Eleanor Roosevelt (EUA) que presidiu o Comitê que redigiu a Declaração.

A Declaração aprovou-se nos moldes das declarações de direitos dos Estados (plano interno), mas é realmente a primeira declaração internacional de direitos humanos. A sua autoridade, como é notório, não advém de norma superior ao ordenamento do Estado nem mesmo do voluntarismo estatal. $\mathrm{O}$ seu fundamento de autoridade é moral e advém da própria dignidade da pessoa humana, que é comum a todos os seres em qualquer parte. O que realmente importa é a condição de pessoa humana.

É consenso na doutrina que a DUDH constitui o ponto de partida do movimento contemporâneo de defesa dos direitos humanos. Pode-se licitamente discordar disso. Pois, como já foi dito, o grande monumento jurídico dos direitos humanos começa com a Carta da ONU. Esta, sim, é a que constitui o verdadeiro ponto de partida, sendo, no entanto, a DUDH a tradução mais afortunada desse espírito protetor da Carta das Nações Unidas ${ }^{19}$.

Não há negar que a Declaração é fruto das tradições jurídicas, políticas e filosóficas ocidentais. A Declaração é censurada, malgrado, desse defeito de origem, espécie de pecado original que acompanha a Declaração desde o seu nascimento. A este respeito, sustenta Wilde que ela realmente se baseia na história e nas tradições de certo grupo de países ocidentais. "Contudo, ela foi expressa de forma aberta e inteligível para povos com outras histórias e nas tradições, que agora compõem o movimento global de direitos humanos ${ }^{20}$ ".

Não é a Declaração, contudo, um documento que parta do zero, do nada, do ponto de vista fatual e instrumental. De efeito, de um lado está a maior tragédia da história da Humanidade, provocada pela insanidade de lideres que promoveram a partir dos seus Estados, alavancados por um positivismo jurídico perverso, a banalização do ser

${ }^{18}$ Eleanor Roosevelt (Estados Unidos) presidiu o Comitê que elaborou a Declaração Universal dos Direitos Humanos. Os outros membros do Comitê foram: René Cassin (França), Charles Malik (Líbano), Peng Chun Chang (China), Hernán Cordero Santa Cruz (Chile), Alexandre Bogomolov e Alexei Pavlov (URSS), Lord Dukeston e Geoffrey Wilson (Reino Unido) e William Hodgson (Austrália).

${ }^{19}$ As lições de Cançado Trindade são também nessa direção: "Em nada surpreende que a Declaração Universal viesse logo a ser tida como uma interpretação autêntica e elaboração da própria Carta das Nações Unidas (no tocante em particular a suas disposições sobre direitos humanos), dando assim conteúdo a algumas de suas normas. A autoridade da Declaração de 1948, nesse sentido, fortaleceu-se, ao ser reconhecida como refletindo normas de direito internacional consuetudinário [há controvérsias]; seus princípios passaram a ser vistos como correspondendo a princípios gerais do direito". Trindade, Antonio A. Cançado. Tratado de direito internacional dos direitos humanos. 1999. p. 22.

${ }^{20}$ Wilde, Ralph. Uma visão geral da Declaração Universal dos Direitos Humanos. In: Direitos humanos: referências essenciais. 2007. p. 106. 
humano, revelando-se, além disso, totalmente possível a destruição da espécie a partir dos ensaios apocalípticos de Nagasaki e Hiroshima; de outro lado está o progressivo acúmulo de documentos originários do Direito interno ocidental consagrando direitos fundamentais, limitadores do poder absoluto de governantes ${ }^{21}$.

A Declaração é o primeiro documento internacional dos direitos humanos que busca integrar, de modo simples e inteligível, todos os direitos humanos em um bloco indivisível. O seu caráter holístico é traço fundamental, posteriormente corroborado por outros documentos jurídicos. Essa natureza totalizante da Declaração é confirmada na I Conferência Mundial de Direitos Humanos das Nações Unidas, celebrada em Teerã, em 196822, cuja Proclamação diz que "Os direitos humanos e as liberdades fundamentais são indivisíveis", logo “[...] a realização dos direitos civis e políticos sem o gozo dos direitos econômicos, sociais e culturais resulta impossível". Na segunda Conferência Mundial de Direitos Humanos (Viena, 1993) reafirma-se na Declaração e Programa de Ação, da mesma forma, a "universalidade", indivisibilidade e a interdependência dos Direitos Humanos. Assim sendo, não cabem na matéria em pauta nem séries infindáveis de gerações históricas de direitos nem muito menos de dimensões mensuráveis que nada significam. A Declaração ou qualquer instrumento internacional de direitos humanos nada tem a ver com a famigerada teoria geracional dos direitos, cuja invencionice remonta a 1979 (cf. Karel Vasak) ${ }^{23}$. A Declaração de Viena é taxativa quanto à unicidade dos direitos humanos:

${ }^{21}$ Cabe repetir que esses documentos são especialmente estes: a Magna Carta de 1215 (Magna Charta Libertatum). [cf. Wilde, p. 88]; Declaração de Direitos elaborada pelo Parlamento da Inglaterra em 1689 (Bill of Rights of 1689); a Declaração de Direitos da Virgínia (1776); as 10 Emendas à Constituição dos Estados Unidos (1789); a Declaração de Direitos do Homem e do Cidadão (Déclaration des Droits de l'Homme et du Citoyen) da Revolução Francesa (1789).

22 A Conferência Internacional de Direitos Humanos realizada em Teerã, de 22 de abril a 13 de maio de 1968, com o propósito de examinar os progressos alcançados nos vinte anos de vigência da DUDH. O segundo parágrafo da Proclamação de Teerã diz: "A Declaração Universal de Direitos Humanos enuncia uma concepção comum a todos os povos de direitos iguais e inalienáveis de todos os membros da família humana e a declara obrigatória para a comunidade internacional". É interessante notar que a sede desta Conferência tenha sido em um Estado islâmico (Irã), não ocidental, portanto.

${ }^{23}$ Em relação a essa tese geracional dos direitos humanos, a argumentação de Cançado Trindade é demolidora. Ele diz que rejeita essa teoria porque considera que o direito à vida pertence a todas as gerações. Eis o que ele diz in verbis: "Eu não aceito de forma alguma a concepção de Norberto Bobbio das teorias de Direito. Primeiro, porque não são dele. Quem formulou a tese das gerações de direito foi o Karel Vasak, em conferência ministrada em 1979, no Instituto Internacional de Direitos Humanos, em Estrasburgo. Pela primeira vez, ele falou em gerações de direitos, inspirado na bandeira francesa: liberté, egalité, fraternité. A primeira geração, liberté: os direitos de liberdade e os direitos individuais. A segunda geração, egalité: os direitos de igualdade e econômico-sociais. A terceira geração diz respeito a solidarité: os direitos de solidariedade. E assim por diante. Em primeiro lugar, essa tese das gerações de direitos não tem nenhum fundamento jurídico, nem na realidade. Essa teoria é fragmentadora, atomista e toma os direitos de maneira absolutamente dividida, o que não corresponde à realidade. Eu conversei com Karel Vasak e perguntei: "Por que você formulou essa tese em 1979?”. Ele respondeu: “Ah, eu não tinha tempo de preparar uma exposição, então me ocorreu fazer alguma reflexão, e eu me lembrei da - bandeira francesa" - ele nasceu na velha Tchecoslováquia. Ele mesmo não levou essa tese muita a sério, mas, como tudo que é palavra "chavão", pegou. Aí Norberto Bobbio começou a construir gerações de direitos etc". Trindade, Antonio Augusto Cançado. A Tese de "Gerações de Direitos Humanos" de Norberto Bobbio. 2018. 
Todos os Direitos humanos são universais, indivisíveis, interdependentes e inter-relacionados. A comunidade internacional deve considerar os Direitos de forma global, justa, equitativa e com igual ênfase. Embora se devam ter sempre presente o significado das especificidades nacionais e regionais e os antecedentes históricos, culturais e religiosos, compete aos Estados, independentemente dos seus sistemas político, econômico e cultural, promover e proteger todos os Direitos do homem e liberdades fundamentais.

Como houvera violação sistemática dos direitos declarados nos Estados, ficou então demonstrada a necessidade de transferir ao Direito internacional a proteção dos Direitos humanos, mesmo a sabendas de que as normas instituídas na matéria ficam sob a responsabilidade dos interessados pelo seu cumprimento. Ao lado disso, criaram-se instâncias de fiscalização e de jurisdição regionais limitadoras do poder de soberania estatal.

René Cassin diz, com muita propriedade, que o domínio do Estado não é absoluto em matéria de Direitos humanos. Se de um lado o Estado exerce de forma exclusiva a competência na promoção e na proteção dos direitos humanos; do outro "[...] ninguém nega na situação atual da sociedade internacional que a comunidade de Estados possui direito de intervenção na referida matéria ${ }^{24 "}$. Pastor Ridruejo, dentre outros doutrinadores, valida a assertiva de que o respeito aos Direitos humanos não é da responsabilidade exclusiva dos Estados, essa responsabilidade é compartilhada porque é "[...] princípio do Direito internacional contemporâneo segundo o qual o respeito aos direitos humanos já não é assunto da jurisdição interna dos Estados no sentido do $\S 2 .^{\circ}$ do art. 7. ${ }^{\circ}$ da Carta das Nações Unidas ${ }^{25}$ ".

Quanto à natureza jurídica da Declaração, de 1948, sabe-se que ela não vincula juridicamente os Estados. Contudo, neste ponto importa muito reconhecer que o conteúdo da DUDH já se encontra em vigor em outros textos, quer de Direito internacional dos Direitos humanos (Pactos), bem como em instrumentos de Direito interno. Celso Mello diz que há consenso em considerar a Declaração como instrumento internacional obrigatório ${ }^{26}$. O grande defeito da Declaração, afirma esse autor, é que ela só cuida dos direitos civis e políticos de tradição liberal ocidental, tratando os direitos econômicos e sociais apenas marginalmente.

${ }^{24}$ Cassin, René. Protección nacional e internacional de los derechos humanos. 1994. p. 388.

Cassin reafirma a tese de que em matéria de Direitos humanos o Estado não tem mais domínio reservado: "Mas as gravíssimas violações à dignidade da pessoa humana - leia-se: nazismo e fascismo -, causas diretas da Segunda Guerra Mundial e os horrores causados por ela têm servido para convencer os Estados da necessidade que intervenha a comunidade internacional a fim de fiscalizar o respeito aos direitos humanos fundamentais" (p. 406). O citado autor diz ainda que "Não se deve esquecer que os pactos internacionais aprovados pelas Nações Unidas em dezembro de 1966 convertem em obrigações jurídicas os enunciados e princípios da Declaração Universal, consequentemente, consideramos que o estabelecido no Pacto Internacional mencionado não constitui um progresso decisivo" (p. 404).

25 Pastor Ridruejo, José Antonio. La protección internacional de los derechos humanos y la cooperación para el desarrollo. 1992. p. 5.

${ }^{26}$ Mello, Celso D. de Albuquerque. Curso de direito internacional público. 2004. p. 870. 
$\mathrm{Na}$ doutrina, há autores que põem as Declarações em geral como responsáveis pela formação do costume internacional, pois consideram que elas ajudam a consolidar o costume internacional. A esse respeito, Celso Mello diz que a doutrina considera a maioria dos princípios consagrados pela Declaração como princípios gerais do direito ou como direito costumeiro ${ }^{27}$.

Cabe recordar que se denomina Carta Internacional dos Direitos humanos o conjunto de documentos formado pela Declaração Universal e pelos dois pactos de 1966: o Pacto Internacional sobre Direitos Econômicos, Sociais e Culturais e o Pacto Internacional sobre Direitos Civis e Políticos. A despeito disso, fica evidente a enorme dificuldade na subordinação dos Estados às normas de direito internacional. A tese de que os pactos compreendem normas de aplicação imediata (direitos civis e políticos) e mediata (direitos econômicos, sociais e culturais) não justifica a divisão de tais direitos em dois documentos. O problema, certamente, passa pelo ônus trazido para o Estado pelos direitos sociais ou coletivos, enquanto os direitos individuais (civis e políticos) demandam apenas a abstenção do Estado. Por essa lógica dissonante seria também necessário dividir a Declaração "Universal” de 1948.

Quanto ao tema da moralidade da Declaração, é óbvio que a moral em geral encerra valores que norteiam e regulam a conduta humana, mas eles não se confundem com os valores e princípios jurídicos. De acordo com Ferreira da Luz, embora o Direito das Gentes não recepcione as normas morais, “[...] há entre o direito e a moral uma conexão necessária" ${ }^{28}$. Aguilar Navarro diz que "A ordem internacional necessita que a moral lhe subministre um espírito, e este deve estar impregnado destas notas: boa-fé, lealdade, justiça, confiança e sinceridade". Esse é também o entendimento de Celso Mello, que vê na Declaração apenas valor meramente moral. Mello afirma que "Ela indica as diretrizes a serem seguidas neste assunto pelos Estados ${ }^{29}$ ".

A Declaração obriga por meio de outros textos em vigor, como já foi mencionado, pois muitas das suas disposições estão codificadas em pactos relativos à matéria. Ela em si não tem autoridade jurídica para obrigar, embora lhe sobre autoridade moral. A Declaração vincula, pois, por via 'oblíqua', quer dizer, por intermédio de outros textos legais obrigatórios. Além de ajudar a formar e consolidar o costume internacional. Convém repetir que há autores (Mello) que consideram as disposições da Declaração princípios gerais do Direito ou como direito internacional consuetudinário ${ }^{30}$.

\footnotetext{
${ }^{27}$ Mello, Celso D. de Albuquerque. Ibidem p. 870.

${ }^{28}$ Luz, Nelson Ferreira da. Introdução ao direito internacional público. 1963. p. 22.

${ }^{29}$ Mello, Celso D. de Albuquerque. Op. Cit. p. 870.

${ }^{30}$ Trindade, Antonio A. Cançado. Tratado de direito internacional dos direitos humanos. 1999. p. 22.
}

Araucaria. Revista Iberoamericana de Filosofia, Politica, Humanidades y Relaciones Internacionales, año 20, $\mathrm{n}^{\circ} 40$. Segundo semestre de 2018. Pp. 209-232. ISSN 1575-6823 e-ISSN 2340-2199 doi: 10.12795/araucaria.2018.i40.09 


\section{Comentários à Declaração Universal dos Direitos Humanos}

Quanto à estrutura, a Declaração é composta de um preâmbulo e da parte dispositiva, que é formada por trinta artigos, sendo o primeiro deles verdadeira declaração de princípios, cujo princípio de igualdade, no que tange ao seu alcance, é versado no dispositivo seguinte (art. 2). Na referida seção articulada contemplam-se os direitos individuais, os coletivos, as obrigações e as condições de exercício dos direitos. De efeito, o documento cuida pormenorizadamente dos direitos civis, que contêm as liberdades fundamentais (arts. 3-20), dos políticos, que são os de soberania (art. 21); dos econômicos, sociais e culturais, que são os direitos coletivos (arts. 22-27). As condições e os limites de exercício dos direitos são tratados nos dispositivos finais do documento (art. 28-30). Ademais, a Declaração estabelece também que ao lado dos direitos há deveres em relação à comunidade política (art. 29). Finalmente, é escusado dizer, o documento em discussão carece de fecho porque não se trata de matéria convencional.

A Declaração registra no Preâmbulo pontos fundamentais do então passado recente, atualmente esses registros ecoam fazendo lembrar que o ser humano não apreende de fato certas coisas, que não se corrige nem mesmo diante da repetição estúpida da banalização da vida dos outros. Esses tantos que perambulam pelo mundo vítimas da miséria, dos que não têm pão, nem teto, nem pátria. Veja-se a atualidade do texto:

[...] o desprezo e o desrespeito pelos direitos humanos resultaram em atos bárbaros que ultrajaram a consciência da Humanidade e que o advento de um mundo em que todos gozem de liberdade de palavra, de crença e da liberdade de viverem a salvo do temor e da necessidade foi proclamado como a mais alta aspiração do ser humano comum. (Grifo do pesquisador).

No trecho acima, formalmente, estão consagradas também as Quatro Liberdades enunciadas pelo presidente dos Estados Unidos, Franklin D. Roosevelt, no seu discurso perante o Congresso (Estado da União), em 6 de janeiro de $1941^{31}$. Que significam essas liberdades? Significariam muito se

${ }^{31}$ Eis o trecho do discurso que trata das referidas liberdades: "No futuro, que procuramos garantir, idealizamos um mundo fundado em quatro liberdades humanas essenciais: A primeira é a liberdade de palavra e de expressão, em qualquer parte do mundo; A segunda é a liberdade de cada um adorar a Deus à sua maneira, em qualquer parte do mundo; A terceira é a liberdade de viver ao abrigo da necessidade, a qual, traduzida em linguagem corrente, significa uma compreensão econômica, que assegure aos habitantes de cada Estado uma vida sã e pacífica, em qualquer parte do mundo; A quarta é a liberdade de viver sem temor, a qual, traduzida em linguagem corrente, significa a redução mundial de armamentos, a tal ponto e de tal maneira que nenhum Estado tenha condições de cometer atos de agressão física contra qualquer vizinho, em qualquer parte do mundo". Trata-se, naturalmente, de outro Presidente dos Estados Unidos e de outra realidade. Na atualidade o discurso é outro. Vale o que interessa ao mercado, o que convém à política de um governo sem dignidade humana.

Araucaria. Revista Iberoamericana de Filosofía, Política, Humanidades y Relaciones Internacionales, año 20, $\mathrm{n}^{\circ} 40$. Segundo semestre de 2018. Pp. 209-232. ISSN 1575-6823 e-ISSN 2340-2199 doi: 10.12795/araucaria.2018.i40.09 
saíssem do papel e ganhassem o mundo. São peremptoriamente as liberdades (de expressão, de culto, de não sentir medo; e de não passar necessidade) que sintetizam as condições imprescindíveis e necessárias à existência digna do ser humano. A Declaração recolhe essa contribuição, bem como as carências de um mundo traumatizado pelo flagelo da guerra que retoma o resgate da dignidade humana a partir da Carta. A Declaração resume o espírito de um movimento de transformação, de renovação e de crença na Humanidade. Pena que esse espírito da Declaração esteja hoje tão longe da realidade, tão distante dos imigrantes que estão à deriva pelos mares do mundo, tão afastado das famílias de imigrantes cujos filhos menores estão separados dos seus pais por determinação do atual governo dos Estados Unidos.

No Preâmbulo da Declaração Universal se reconhece que a pessoa humana tem dignidade 32 e direitos, os quais fundamentam a liberdade, a justiça e a paz na sociedade internacional. Abre-se o documento, pois, com o asserto cabal de que o ser humano é o centro do processo, o sujeito principal dessa e de toda e qualquer sociedade. Considera-se por tal razão que o desconhecimento e o menosprezo dos direitos humanos originam atos bárbaros, como o foram os perpetrados durante a Segunda Guerra Mundial e como o são a miséria, a fome, e o degradante fenômeno migratório no presente. Proclama-se então como a mais alta aspiração do ser humano o advento de um mundo provido de liberdades civis e de dignidade; um espaço, portanto, livre do temor e da miséria no qual todos usufruam da liberdade de palavra e de crença.

Ainda no Preâmbulo, considera-se essencial a vigência do Estado democrático de direito na proteção da pessoa humana; caso contrário, considera-se legítima a resistência contra a tirania e a opressão. Reputa-se essencial também a promoção do desenvolvimento de relações amistosas entre as "Nações"

${ }^{32}$ Além da Declaração Universal dos Direitos Humanos (1948), a dignidade da pessoa humana aparece como garantia objetiva em muitos instrumentos internacionais: 1) Pacto de Direitos Civis e Políticos (1966): preâmbulo e art. 10-1..;2); Pacto de Direitos Econômicos, Sociais e Culturais (1966): preâmbulo e art. 10-1. ; 3) Declaração e Programa de Ação de Viena (1993): diz que "[...] todos os direitos humanos têm sua origem na dignidade e no valor da pessoa humana". Quanto à dignidade como fundamento dos Direitos humanos, Peces-Barba (2003, p. 13) afirma que: "A modernidade considera-se desde o humanismo, isto é, a partir da idéia do homem como centro do mundo e que se distingue dos demais animais com certos traços que implicam a marca da sua dignidade. [...] a dignidade humana é o fundamento da ética pública laica, que se vai construindo durante séculos, a partir do século XVI [cf. Maquiavel], com especial relevância para o modelo de grande contribuição da Ilustração. Kant reunirá bem essa dupla vertente ao responder à pergunta Que é a Ilustração? na qual vincula o homem (sendo que para ele o homem é um fim em si mesmo e não tem preço) à idéia de autonomia no sentido de que não necessita de andador e pode caminhar por si mesmo".

33 Por negligência no domínio da tecnologia jurídica do Direito das Gentes designam-se as "Nações" como sujeitos, mas a referência aqui, e noutras partes da Declaração, é apropriadamente aos Estados, que são os verdadeiros sujeitos de Direito internacional. As "Nações" nesse caso, como bem o sabem os juristas, não são sujeitos. Aliás, a "Nação" é conceito antropológico ou cultural, não jurídico. De modo que um Estado pode ser formado por várias nacionalidades.

Araucaria. Revista Iberoamericana de Filosofia, Política, Humanidades y Relaciones Internacionales, año 20, $\mathrm{n}^{\circ} 40$ Segundo semestre de 2018. Pp. 209-232. ISSN 1575-6823 e-ISSN 2340-2199 doi: 10.12795/araucaria.2018.i40.09 
[...] os povos das Nações Unidas reafirmaram, na Carta, sua fé nos direitos humanos fundamentais, na dignidade e no valor do ser humano e na igualdade de direitos entre homens e mulheres [...]. A Assembléia Geral proclama a presente Declaração Universal dos Direitos Humanos como o ideal comum a ser atingido por todos os povos e todas as Nações [sic], com o objetivo de que cada indivíduo e cada órgão da sociedade, tendo sempre em mente esta Declaração, se esforce, através do ensino e da educação, por promover o respeito a esses direitos e liberdades.

Quanto à parte dispositiva da Declaração, o artigo primeiro destacase pelo seu ingente significado no documento em discussão. Tal preceito estabelece ipsissima verba que "Todos os seres humanos nascem livres $e$ iguais em dignidade e direitos. São dotados de razão e consciência e devem agir em relação uns aos outros com espírito de fraternidade". (Grifo nosso). Do ponto de vista da mais alta aspiração humana, este é o artigo medular da Declaração de direitos, pela afirmação de que os seres humanos nascem livres, iguais, dotados de dignidade humana, sendo detentores de direitos que devem ser exercidos com espírito de fraternidade, em virtude da sua natureza racional. Nada obstante, propósito e realidade não se confundem. Cortina leciona a respeito da imposição de certa ética utilitarista como base da Declaração, diz ela que "A dignidade humana é o fundamento desses direitos, não a utilidade que deles pode derivar. Os direitos são exigências da dignidade, não recursos, instrumentos dos que se extrai utilidade" ${ }^{34}$.

Refere-se o documento, portanto, a declaração fundamental de princípios, de cunho iluminista, que toma a razão e a consciência ${ }^{35}$ como condições determinantes da espécie humana. Por que a racionalidade deveria ser determinante de humanidade? Por esse prisma um doente mental estaria excluído da espécie humana, do contrato social (contratualismo) e dos direitos humanos?

Todos os seres humanos têm, portanto, direitos pelo fato de pertencerem ao gênero humano, sejam eles racionais ou não. Dentre esses direitos estão, segundo a Declaração, a liberdade e a igualdade, que não são de forma alguma direitos inatos. São direitos reconhecidos internacionalmente como inevitáveis na luta pela paz, pela convivência pacífica entre os Estados e pelo desenvolvimento integral da pessoa humana. Além deles está, obviamente, o espírito de fraternidade.

\footnotetext{
34 Cortina, Adela. Las fronteras de la persona: el valor de los animales, la dignidad de los humanos. 2009. p. 39.

35 Conta Wide (2007, p. 106) que "Originalmente foi escrito 'sendo dotados pela natureza de razão e consciência, dando à palavra 'natureza' o sentido de natureza humana (a característica essencial do homem) ou de Deus. Os redatores rejeitaram a 'natureza', para que a Declaração não abrigasse uma definição particularmente rígida da base dos direitos humanos".
} 
Evidentemente, essa Declaração de 1948 é incompatível com a bestialidade e a desumanidade dos atos que foram perpetradas durante a Segunda Guerra Mundial e dos que continuam sendo praticados ainda hoje. A Declaração reafirma a racionalidade e a consciência dos seres humanos - descontado, naturalmente, o que foi dito acima em relação à condição de racionalidade dando conta que somente o ser humano é capaz de perceber o que é moralmente certo ou errado quando age em relação aos outros.

$\mathrm{O}$ direito de igualdade, afirmado acima, vem disciplinado no parágrafo primeiro, do artigo 2 da Declaração, que reafirma a capacidade de toda a pessoa humana de "[...] gozar os direitos e as liberdades estabelecidos nesta Declaração, sem distinção de qualquer espécie, seja de raça, cor, sexo, idioma, religião, opinião política ou de outra natureza, origem nacional ou social, riqueza, nascimento, ou qualquer outra condição". Como se vê, o artigo em apreço determina o alcance do direito à igualdade, enunciado no dispositivo anterior. No papel, tal direito alcançaria, sem distinção, de qualquer natureza, todos os seres humanos em qualquer parte do mundo, inclusive os apátridas que se acham à toa, ao deus-dará pelos mares do mundo e que se lhes nega, sistematicamente, um porto de chegada ou uma mão estendida em sinal de socorro. Se o que importa é o ser humano, como tanto se declara e se positiva, então há um incompreensível e profundo abismo entre o que está positivado e a realidade.

$\mathrm{O}$ direito à igualdade é inerente à pessoa humana, independente da sua condição diferenciada a pessoa tem, segundo o texto, igual valor ou qualidade. Para ser fiel à realidade, o propósito da Declaração fica apenas na humanidade de papel, como ficou a Declaração francesa. Diz-se, contudo, que essa paridade se reflete bem na denominada igualdade de oportunidades, que está na base do regime democrático no Estado de direito. $\mathrm{O}$ artigo estabelece lista não exaustiva de distinções vedadas pela Declaração.

A par do direito à liberdade, estabelecido no dispositivo inicial, os preceitos seguintes estabelecem o núcleo comum dos direitos humanos, pois somente podem ser ditos internacionais os direitos imprescindíveis, sem os quais a pessoa perde a condição de humanidade. Esses direitos, além da liberdade, são estes: a) o direito à vida, a qual deve ser digna e dotada de personalidade jurídica em todo o lugar (arts. 3 e 6$)^{36} ; \mathrm{b}$ ) o direito a não ser mantido à escravidão nem torturado (arts. 4 e 5) ${ }^{37}$; c) o direito ao devido processo legal (arts. 8 a 11) ${ }^{38}$.

\footnotetext{
${ }^{36}$ Como se pode verificar no dispositivo seguinte, o direito à vida vem acompanhado do direito à liberdade: "Art. 3. Todo ser humano tem direito à vida, à liberdade e à segurança pessoal. Art. 6. Todo ser humano tem o direito de ser, em todos os lugares, reconhecido como pessoa perante a lei”.

37 Os artigos que tratam da escravidão e da tortura são, além de mais amplos, proibitivos: "Art. 4. Ninguém será mantido em escravidão ou servidão; a escravidão e o tráfico de escravos serão proibidos em todas as suas formas. Art. 5. Ninguém será submetido à tortura nem a tratamento ou castigo cruel, desumano ou degradante".

38 A Declaração garante a prestação jurisdicional efetiva da ordem jurídica vigente contra 
O resto da seção relativa às liberdades fundamentais, que vai até o artigo 20, cuida de garantir, dentre outros, os direitos à privacidade, à liberdade de locomoção (de pensamento, de expressão, de religião, de reunião), à residência, à propriedade, ao asilo político, à nacionalidade estatal, a constituir família. Com a inserção da nacionalidade, como direito humano, a Declaração tem por fito combater a apatridia, já a família é considerada "o núcleo natural e fundamental da sociedade".

No que se refere aos direitos políticos, (os quais são direitos históricos, segundo Marshall, porque formados somente no decorrer do século $\mathrm{XIX}^{39}$ ), a Declaração os trata em um único dispositivo (art. 20). Os direitos políticos são os de soberania, que incluem a participação efetiva no processo decisório da sociedade política. O parágrafo terceiro do artigo 21 se refere com propriedade a esse processo decisório, destacando o povo como fonte originária do poder: "A vontade do povo será a base da autoridade do governo; esta vontade será expressa em eleições periódicas e legítimas, por sufrágio universal, por voto secreto ou processo equivalente que assegure a liberdade de voto".

No tocante aos direitos coletivos, a Declaração reafirma a prerrogativa de todo o ser humano gozar, de acordo com as possibilidades de cada Estado, dos direitos econômicos, sociais e culturais indispensáveis à sua dignidade. Esses direitos são, como é sabido, de formação tardia na história estatal moderna, mas os primeiros que ingressam na seara internacional em virtude da criação da Organização Internacional do Trabalho, a mesma primazia vale para a inserção deles no Brasil, pois ingressam antes de os direitos políticos ${ }^{40}$, embora

as violações dos direitos fundamentais, vedando-se a prisão arbitrária. Mas se porventura houver infração da lei, nessa hipótese toda a pessoa humana tem direito a julgamento por parte de um tribunal independente e imparcial. No art. 11 garantem-se a presunção de inocência, bem como os princípios da reserva legal e da anterioridade da lei:. Diz o citado artigo: "1. Todo ser humano acusado de um ato delituoso tem o direito de ser presumido inocente até que a sua culpabilidade tenha sido provada, de acordo com a lei, em julgamento público no qual lhe tenham sido asseguradas todas as garantias necessárias à sua defesa. 2. Ninguém poderá ser culpado por qualquer ação ou omissão que, no momento, não constituíam delito perante o direito nacional ou internacional. Também não será imposta pena mais forte do que aquela que, no momento da prática, era aplicável ao ato delituoso".

39 No ensaio Citizenship and Social Class (1950) Marshall aborda o tema da cidadania britânica à luz das mudanças ocorridas durante o século XIX. Nesse ensaio, Marshall, considerando apenas a sociedade britânica, elabora uma teoria geral da cidadania. Ele afirma que a cidadania se desenvolve historicamente nos séculos XVIII (Direitos civis); XIX (Direitos políticos) e XX (Direitos sociais). No ensaio, ele examina de modo original as relações entre cidadania e classe social a partir da perspectiva histórica e comparada. Marshall nesse ensaio introduz o conceito de Direitos sociais. A respeito dos direitos políticos, ele diz que: "Tanto por su carácter como por su cronología, la historia de los derechos políticos es diferente. Como ya apunté, el período de formación empezó en los albores del siglo XIX, cuando los derechos civiles asociados al status de libertad habían adquirido la sustancia que nos permite hablar de un status general de ciudadanía”. Cf. Marshall, T. H.; Bottomore, Tom. Ciudadanía y clase social. 2005. p. 29.

40 No Brasil, a primeira experiência democrática é a de 1948-1964, período no qual se inserem, em parte, os direitos políticos, que são logo destruídos pelo regime autoritário que se estabelece a partir de 1964. O fim do regime militar e a redemocratização possibilitam o restabelecimento e o alargamento dos direitos políticos, que ainda estão em expansão por causa da inserção de formas 
instrumentalizados politicamente. Eles incluem, dentre outros, o direito à educação, à saúde, ao trabalho, ao salário justo, ao lazer, à participação na vida cultural da comunidade (Cf. arts. 22 a 27 da Declaração).

Reafirme-se que, em condições ideais, a todo o direito, seja ele individual ou coletivo, corresponde exatamente um dever do cidadão em relação à sociedade. Tome-se de um lado, verbi gratia, o caro direito à Educação, que é um direito social fundamental, do outro lado deve estar o dever de instrução, que é obrigação individual. Porque de não ser assim, nenhum catálogo de prerrogativas seria capaz de sobreviver, se do outro lado não houvesse a respectiva declaração de deveres a serem cumpridos pelas pessoas.

Em última instância, a Declaração Universal é Carta de princípios na qual se estabelecem direitos essenciais à pessoa humana (individuais e coletivos), fundamentados na dignidade humana, que devem ser observados por todos.

\section{Considerações finais}

A Declaração Universal dos Direitos Humanos é invocada em todo o mundo pelo reconhecimento da sua incontestável autoridade moral. Além de ser pioneira no que se refere à instituição do catálogo de direitos no mundo, de ser representativa da condição humana; de ser, quem sabe, a única possível neste mundo tão complexo, tão cheio de contrastes e de relativismos. É a primeira a elevar a dignidade da pessoa humana ao ápice (fundamento), a sobrepor-se porque declara direitos essencialíssimos ao ser humano de maneira simples e integral.

Embora o texto não seja juridicamente vinculante para os Estados, visto que é mera Declaração, ele representa o que deveria vincular, o que os Estados deveriam ter convertido em tratado, o que deveria ser lei interna e internacional, porque diz respeito a todos os seres humanos (racionais ou não), estejam eles dentro dos seus Estados ou fora deles. É a Declaração de direitos da pessoa humana em todas as situações e lugares, do cidadão do mundo com direito à hospitalidade, como diria Kant, pois ela abraça a completude dos direitos de cidadania.

A DUDH é o paradigma "irrepetível" de um momento histórico particular da consciência humana, é o tratado que deveria ser e não foi, é a declaração

diretas e inovadoras de participação popular. Em rigor, pode-se dizer que os direitos políticos no Brasil Império eram embustes, fraudes mesmo. Assevera-se isso com base em dados objetivos, como o de que $85 \%$ do povo era formado por analfabetos; que o votante era influenciado na hora de votar; que no processo eleitoral se firmaram figuras estrambólicas, especialistas em burlar as eleições. De fato, nesse período surgem personagens como a do 'cabalista', que fornecia a prova da renda do votante e garantia o voto dos alistados, e a do 'fósforo'. "Se o alistado não podia votar por qualquer razão, inclusive por ter morrido, comparecia o fósforo, isto é, uma pessoa que se fazia passar pelo verdadeiro votante". Cf. Carvalho, Jose Murilo de. Cidadania no Brasil: o longo caminho. 2005. p. 34. 
que deveria ser escrita na Constituição Mundial que não existe ainda, é o mais luminoso documento internacional do movimento que começa com a Carta das Nações Unidas, cujo brilho fulgurante ilumina todos os recantos onde os direitos são violados. Se a Declaração fosse um tratado internacional, não seria o que ela é atualmente, não representaria para a Humanidade o que representa. Se a Declaração fosse um tratado já teria sido desrespeitada, transgredida, violada. Mas, por fortuna, a Declaração não é norma convencional vinculante. Por essa razão não pode ser violada, nem ferida, nem tem o destino das leis caducas. Seu destino é o da imortalidade em razão da sua essencialidade histórica e da sua relevância moral e metajurídica. 


\section{Referências:}

Abranches, C. A. Dunshee de. Proteção internacional dos direitos humanos. Rio de Janeiro; São Paulo: Freitas Bastos, 1964.

Appiah, Kwame Anthony. Cosmopolitismo: la ética en un mundo de extraños. Trad. Lilia Mosconi. Buenos Aires: Katz, 2007.

Bloch, Ernst. Derecho natural y dignidad humana. Trad. Felipe Gonzalez Vicén. Madrid: Dykinson, 2011.

Bobbio, Norberto. Teoria geral da política: a filosofia política e as lições dos clássicos. Rio de Janeiro: Campus, 2000.

Boson, Gerson de Brito Mello. Internacionalização dos direitos do homem. São Paulo: Sugestões Literárias, 1972.

Cassin, René. "Protección nacional e internacional de los derechos humanos". In: Veinte años de evolución de los derechos humanos. México: UNAM, 1994. pp. 399-407.

Carvalho, Jose Murilo de. Cidadania no Brasil: o longo caminho. 7. ed. Rio de Janeiro: Civilização Brasileira, 2005.

Cortina, Adela. Las fronteras de la persona: el valor de los animales, la dignidad de los humanos. Madrid: Taurus, 2009.

Luz, Nelson Ferreira da. Introdução ao direito internacional público. São Paulo: Saraiva, 1963.

Jullien, François. De l'universel, de l'uniforme, du commun et du dialogue entre les cultures. Paris: Fayard, 2008.

Marshall, T. H.; Bottomore, Tom. Ciudadania y clase social. Trad. Antonio Bonanno. Buenos Aires: Losada, 2005.

Mello, Celso D. de Albuquerque. Curso de direito internacional público. 15. ed. Rio de Janeiro: Renovar, 2004. 2v.

Mello, Rubens Ferreira de. Textos de direito internacional e de historia diplomática de 1815 a 1949. Rio de Janeiro: A. Coelho Branco Filho, 1950.

Pastor Ridruejo, José Antonio. La protección internacional de los derechos humanos y la cooperación para el desarrollo. IHLADI, XVII Congreso, Cáceres (España), 1992. 11 pp. (Separata).

Rezek, José Francisco. Direito internacional publico - curso elementar. 8. ed. rev. e atual. São paulo: Saraiva, 2000.

Spiropoulos, Jean. L'individu et le droit international. Recueil des Cours, Tome 30, vol. V, pp. 191-270, 1929.

Trindade, Antonio A. Cançado. Tratado de direito internacional dos direitos humanos. Porto Alegre: Sergio Fabris, 1999. 
Trindade, Antonio Augusto Cançado. A Tese de "Gerações de Direitos Humanos" de Norberto Bobbio. Disponível em: <www.dhnet.org.br/ direitos/militantes/ cancadotrindade/cancado_bob.htm>. Acesso em: 20 jul. 2018

Wilde, Ralph. "A Declaração Universal dos Direitos Humanos". In: Poole, Hilary (Org.). Direitos humanos: referências essenciais. Trad. Fábio Larsson. São Paulo: Edusp, 2007. pp. 83-161. (Série Direitos humanos, 3). 